\title{
Thermodynamics of the Heart
}

\author{
Uehara, Mituo and Sakane, Kumiko Koibuchi \\ Universidade do Vale do Paraíba \\ Brazil
}

\section{Introduction}

It is well known that heart and respiratory rates increase with increasing the level of physical exercise. The heart rate (heart beats per minute) is related to the cardiac output (volume of blood pumped by the heart per unit time) and the respiratory rate is related to the rate of oxygen consumption. Therefore there is relation between cardiac output and oxygen consumption, as confirmed by many experiments (Milnor, 1990).

Adolph Fick, German physiologist, was the first to relate, mathematically, cardiac output to gas exchange in the lungs. In 1870, he derived the equation (Acierno, 2000; Shapiro, 1972)

$$
\mathrm{Q}=\frac{\mathrm{q}}{\left[\mathrm{O}_{2}\right]_{\mathrm{pv}}-\left[\mathrm{O}_{2}\right]_{\mathrm{pa}}},
$$

where $\mathrm{Q}$ is the cardiac output, $\mathrm{q}$ the rate of oxygen consumption, $\left[\mathrm{O}_{2}\right]_{\mathrm{pv}}$ the $\mathrm{O}_{2}$ concentration in the pulmonary veins, and $\left[\mathrm{O}_{2}\right]_{\mathrm{pa}}$ the $\mathrm{O}_{2}$ concentration in pulmonary arterial blood.

Fick's equation is a landmark of the history of cardiology because it provided the theoretical basis for the measurement of cardiac output in intact animals and people. The first measurement of cardiac output in humans was made in 1930 (Acierno, 2000), sixty years after the publication of Fick's theoretical derivation, which marks the beginning of modern cardiology.

The cardiac output is related to the work that the heart does in pumping blood to the vascular system. A thermodynamic approach has been applied to estimate energy gain and the work performed by the heart (Blick \& Stein, 1977). Recently, by viewing the heart as a thermodynamic engine, a new equation, which relates cardiac output to oxygen consumption, has been derived (Uehara et al., 2008). In this work, the new equation is applied to derive the behavior of important physiological quantities of the cardiovascular system during exercise, such as the efficiency index of the heart, and to discuss the conditions for the linearity of the relation between cardiac output and oxygen consumption. It is shown that the efficiency index of the heart decreases with increasing the exercise level. Furthermore, the referred equation is generalized to include pathological situations such as, for example, ischemic heart disease.

\section{The cardiovascular system}

The cardiovascular system is diagrammatically represented in Figure 1. The heart consists of a double pump, the left side of the heart or the left heart and the right side of the heart or the 
right heart, connected in series by two independent circulatory systems, the pulmonary circulation and the systemic circulation. The left heart pumps blood through the systemic circulation and the right heart pumps blood through the pulmonary circulation. Each heart has two chambers, the atrium and the ventricle, which periodically contract and relax. The movements of contraction and relaxation are, respectively, systole and diastole. The systole and diastole of the atria and of the ventricles are synchronized so that when the atria are contracting the ventricles are relaxed, and vice-versa. The atrium receives and stores blood during the ventricular contraction, and blood flows from the atrium to the ventricle during ventricular relaxation. The right ventricle propels blood through the blood vessels of the lungs (the pulmonary circulation) and the left ventricle propels blood to all other tissues (the systemic circulation). The blood conveys nutrients and oxygen to the cells. Inside the cells, oxygen and nutrients react chemically with release of energy, which is used by the cells, and production of water and carbon dioxide $\left(\mathrm{CO}_{2}\right)$ that are disposed by the cells to the blood, so that the concentration of oxygen in the blood decreases and the concentration of carbon dioxide increases as the blood flows through the systemic circulation. In the pulmonary circulation oxygen from the pulmonary alveoli is added to blood and carbon dioxide comes out from the blood and gets into the pulmonary alveoli to be exhaled. The freshly oxygenated blood flows from the pulmonary circulation to the left side of the heart, fills the left ventricle, and a new cardiac cycle begins.

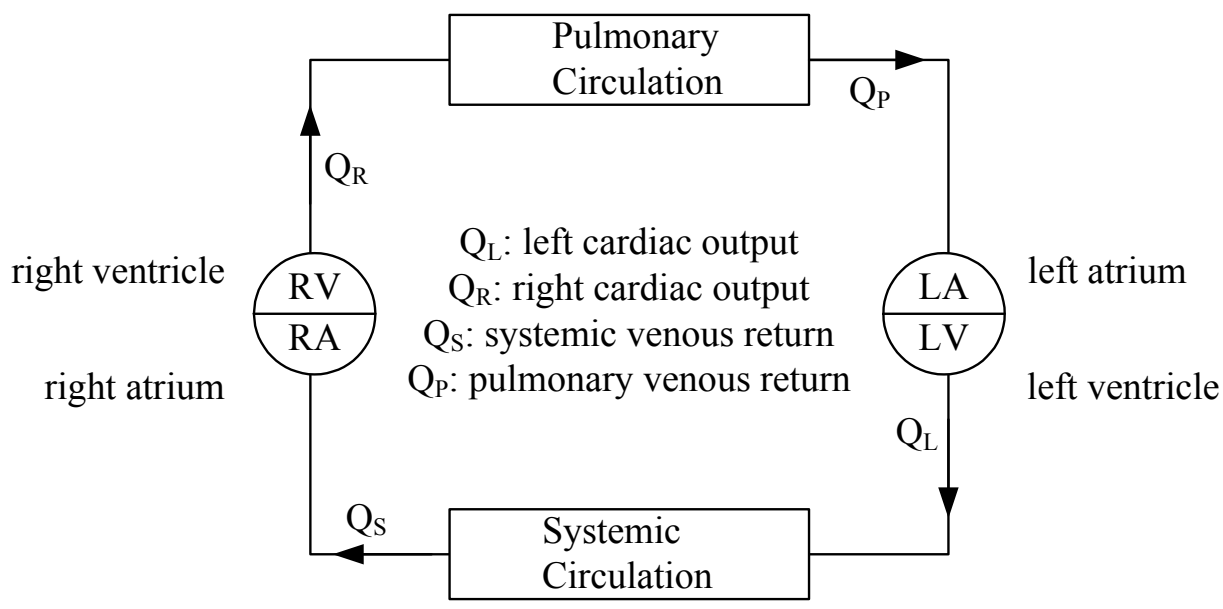

Fig. 1. Diagrammatic representation of the cardiovascular system

In Figure $1, Q_{L}$ denotes the cardiac output of the left heart, $Q_{R}$ the cardiac output of the right heart, $Q_{P}$ the blood flow from the pulmonary circulation, and $Q_{S}$ the venous return (blood flow from the systemic circulation). A system of valves ensures that blood flows in the direction indicated in Fig. 1. We consider time-averaged values of blood flows over a cardiac period. During transient phenomena, these time-averaged blood flows are functions of time and satisfy a set of differential equations that are useful for discussing the stability of the system (Uehara and Sakane, 2003). In a steady state of the cardiovascular system the timeaveraged blood flow is the same throughout the system, that is

$$
\mathrm{Q}_{\mathrm{L}}=\mathrm{Q}_{\mathrm{R}}=\mathrm{Q}_{\mathrm{P}}=\mathrm{Q}_{\mathrm{S}}=\mathrm{Q}
$$


In this work we shall consider only steady-states of the cardiovascular system and timeaveraged values of time dependent quantities.

The cardiac output of a ventricle is given by

$$
\mathrm{Q}=\mathrm{f} \mathrm{S}
$$

where $\mathrm{f}$ is the cardiac rate (number of heart beats per minute) and $\mathrm{S}$ the stroke volume (volume of blood ejected by the ventricle in a cardiac cycle).

The blood arterial pressure oscillates periodically between a maximum called systolic pressure and a minimum called diastolic pressure. The mean arterial pressure in the systemic circulation is approximately given by (Berne\&Levy, 2001)

$$
\mathrm{P}_{\mathrm{sa}}=\mathrm{P}_{\mathrm{sd}}+\frac{\mathrm{P}_{\mathrm{ss}}-\mathrm{P}_{\mathrm{sd}}}{3}
$$

where $\mathrm{P}_{\mathrm{sa}}$ is the mean arterial pressure, $\mathrm{P}_{\mathrm{sd}}$ the diastolic arterial pressure and $\mathrm{P}_{\mathrm{ss}}$ the systolic arterial pressure.

The left ventricle pumps blood into the arteries of the systemic circulation, which already contain blood at pressure $\mathrm{P}_{\mathrm{sa}}$. The blood pressure falls along the systemic circulation at the end of which there are two large veins (venae cavae). These large veins convey blood to the right atrium. The blood flow to the atrium, denoted by $\mathrm{Q}_{\mathrm{S}}$ is called systemic venous return. The term "return" refers to the fact that the blood is returning to the heart and the term "venous" indicates that the blood vessels that convey blood to the right atrium are veins. The venous pressure $P_{\mathrm{sv}}$ at the venae cavae is very low as compared to the systemic arterial pressure $P_{\text {sa. }}$. The systemic vascular resistance $R_{S}$ is defined by (Hoppensteadt \& Peskin, 1992)

$$
\mathrm{R}_{\mathrm{S}}=\frac{\mathrm{P}_{\mathrm{Sa}}-\mathrm{P}_{\mathrm{SV}}}{\mathrm{Q}_{\mathrm{S}}}
$$

Since the venous pressure $P_{s v}$ is much smaller than the arterial pressure Psa, it can be neglected, so that usually $R_{S}$ is calculated as $R_{S}=P_{\text {sa }} / Q_{S}$.

\section{Relation between cardiac output and oxygen consumption}

We shall derive a relation between cardiac output and oxygen consumption by considering the efficiency of the heart in pumping blood to the vascular system.

\subsection{Energy consumption}

Principles and concepts of thermodynamics can be applied to the heart in order to determine the energy expended in pumping blood. By considering all known sources of energy gain or loss by the heart, it can be shown that many terms are negligibly small (Blick \& Stein, 1977). In this work we shall consider only the dominant terms.

Energy provided by food is stored in the body as internal energy. Among the various factors that can change the heart internal energy, the dominant one is the metabolic energy change. This contribution arises from the oxidation of carbohydrates (starch and sugars), fats, and proteins. For glucose $\left(\mathrm{C}_{6} \mathrm{H}_{12} \mathrm{O}_{6}\right)$, a form of sugar used in intravenous feeding, the oxidation equation is (Cameron et al., 1999)

$$
\mathrm{C}_{6} \mathrm{H}_{12} \mathrm{O}_{6}+6 \mathrm{O}_{2} \rightarrow 6 \mathrm{CO}_{2}+6 \mathrm{H}_{2} \mathrm{O}+686 \mathrm{kcal}
$$


where $686 \mathrm{kcal}(\mathrm{kcal}=4.184 \mathrm{~kJ})$ is the energy released by one mole of glucose.

Coronary blood flowing through the myocardium delivers oxygen and other substances to the cells of the cardiac muscle. In the interior of the cells, nutrients react chemically with oxygen and energy is released.

From Equation (6) it can be seen that the energy released per liter of oxygen consumed, in the oxidation of glucose, is $5.1 \mathrm{kcal} /$ (liter of oxygen). For a typical diet the energy released is about $5.0 \mathrm{kcal} /$ (liter of oxygen) (Milnor, 1990; Cameron et al., 1999).

The metabolic process we have just described is called aerobic metabolism, which occurs in the presence of free oxygen. Energy can also be provided by anaerobic metabolism, which occurs in the absence of free oxygen.

The rate of oxygen consumption by the heart $\left(\Omega_{\mathrm{H}}\right)$ is a fraction of the total rate of oxygen consumption $(\Omega)$ by the body and can be written as

$$
\Omega_{\mathrm{H}}=\mathrm{c} \Omega
$$

where $\mathrm{c}<1$.

Assuming that the energy consumed by the heart is provided only by aerobic metabolism, we write

$$
\mathrm{P}=\mathrm{Ec} \Omega
$$

where $\mathrm{P}$ is the power consumed by the heart and $\mathrm{E}$ is the metabolic energy released per liter of oxygen consumed. Part of the power consumed by the heart is used to perform external work in the form of ventricular contractions to pump blood.

The assumption that the energy consumed by the heart is generated by aerobic metabolism is supported by experimental observations. Vary and collaborators have analyzed the aerobic and anaerobic processes of energy production in the cardiac muscle and concluded that the aerobic metabolism corresponds to more than $90 \%$ of the total energy produced (Vary et al., 1981). In the transition from the rest condition to exercise the ventricles must generate sufficient power to maintain blood pressure and organ perfusion, which requires tight coupling of the transfer of chemical energy to mechanical power. This controlled energy transfer can require up to fivefold increase in cardiac power generation and oxygen consumption, yet appears to occur without anaerobic metabolism (Zhou et al., 2006; Sharma et al., 2005).

\subsection{Work done by the heart}

Among the various forms of work that are performed by the heart, many of them give rise to terms that are negligibly small (Blick \& Stein, 1977). In this work we shall consider only the work in pumping blood, which is the dominant term.

Each ventricle pumps blood to the corresponding arterial system, which already contains blood at a pressure that oscillates periodically. The maximum and minimum arterial pressures are called the systolic and diastolic pressure, respectively. The process of filling the left ventricle and the process of blood ejection to the vascular system can be described by a pressure-volume diagram as shown in Fig.2, which illustrates the cardiac cycle of the left ventricle (Burkhoff \& Sagawa, 1986). The line DA describes the filling of the ventricle, in which the volume increases from $V_{\mathrm{ES}}$ (end systolic volume) to $\mathrm{V}_{\mathrm{ED}}$ (end diastolic volume). The vertical line $\mathrm{AB}$ describes the isometric increase of the ventricular pressure, during which the volume remains constant, because the inflow and the outflow valves are closed. 


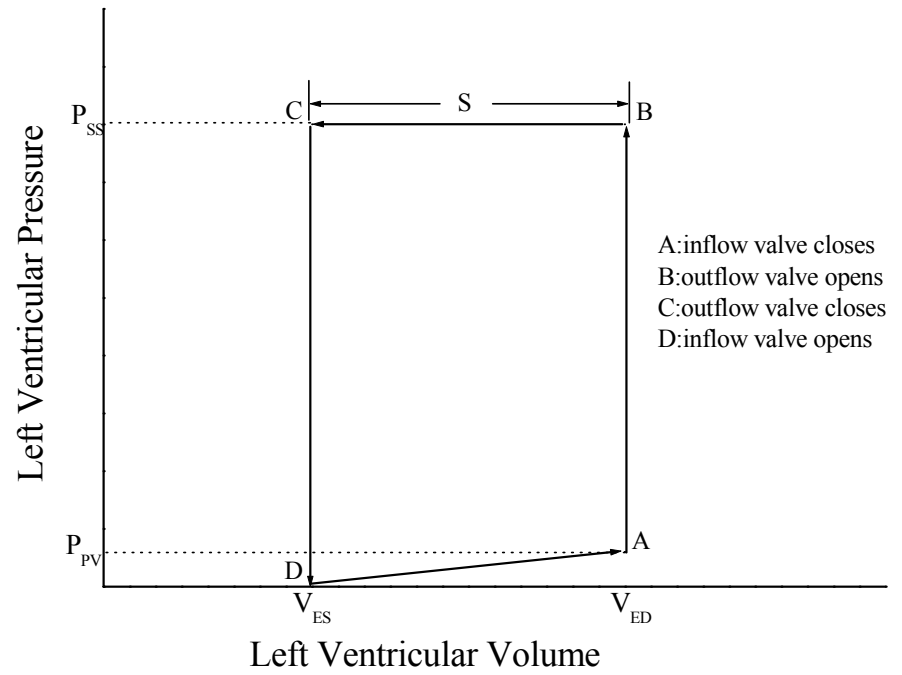

Fig. 2. Pressure-volume diagram of the left ventricle. $\mathrm{P}_{\mathrm{ss}}$ : systemic systolic pressure; $\mathrm{P}_{\mathrm{pv}}$ : pulmonary venous pressure; $\mathrm{V}_{\mathrm{ES}}$ : end systolic volume; $\mathrm{V}_{\mathrm{ED}}$ : end diastolic volume; $\mathrm{S}$ : stroke volume.

The horizontal line BC describes the ejection of blood to the vascular system. The volume of blood ejected $S=V_{E D}-V_{E S}$ is the stroke volume. $V_{E S}$ is the volume of blood that remains in the left ventricle in the end of the ejection process. The descending vertical line CD describes the isometric decreases of the ventricular pressure.

During the filling process, described by the line DA, blood flows from the pulmonary veins into the left ventricle, which is relaxed. Thus, the filling pressure is equal to the pulmonary venous pressure $P_{p v}$, which is much smaller than the arterial pressure of the systemic circulation. During the ejection process, described by the line $\mathrm{BC}$, the ventricular pressure must be larger than the arterial pressure of the systemic circulation, which varies between its systolic and diastolic values. The time-average of the ventricular pressure, during the ejection process, is approximately equal to the systemic systolic pressure $\mathrm{P}_{\mathrm{ss}}$. In Figure 2, for simplicity, the ventricular pressure is assumed to be constant during the ejection process.

From the pressure-volume diagram of the left ventricle it can be seen that the external work done by the left ventricle in a cardiac cycle is approximately given by (Uehara et al., 2008; Burkhoff \& Sagawa, 1986)

$$
\mathrm{W}_{\mathrm{L}}=\mathrm{SP}_{\mathrm{SS}}
$$

where $\mathrm{W}_{\mathrm{L}}$ is the work done by the left ventricle, $\mathrm{S}$ the stroke volume, and $\mathrm{P}_{\mathrm{ss}}$ is the systemic systolic pressure of blood in the large arteries of the systemic circulation.

The pressure-volume diagram of the right ventricle is similar to that of the left ventricle, but the time average of the right ventricle pressure during the ejection of blood is approximately equal to the pulmonary systolic pressure $\mathrm{P}_{\mathrm{ps}}$, which is about seven times smaller than the systolic systemic pressure $\mathrm{P}_{\mathrm{ss}}$ (Higginbotham et al., 1986; Milnor, 1990). Thus, the external work done by the right ventricle in a cardiac cycle can be approximately given by 


$$
\mathrm{W}_{\mathrm{R}}=\mathrm{SP}_{\mathrm{ps}},
$$

so that the total external work done by the heart in a cardiac cycle is

$$
\mathrm{W}=\mathrm{W}_{\mathrm{L}}+\mathrm{W}_{\mathrm{R}}=\mathrm{S}\left(\mathrm{P}_{\mathrm{ss}}+\mathrm{P}_{\mathrm{ps}}\right)
$$

and the average power generated by the heart is

$$
\mathrm{Wf}=\left(\mathrm{P}_{\mathrm{ss}}+\mathrm{P}_{\mathrm{ps}}\right) \mathrm{Sf}
$$

where $\mathrm{f}$ is the heart rate.

The mechanical energy output of the heart to the systemic and pulmonary blood is subsequently converted to thermal energy throughout the body by the action of viscous dissipation of the blood.

\subsection{Heart efficiency}

The heart can be viewed as a thermodynamic engine that transforms part of the expended power P into external power Wf, given by Equation (12). The mechanical efficiency of the heart can be defined in several ways. It is reasonable to define it as the mechanical power generated by the heart to pump blood divided by the metabolic energy rate consumed by the heart muscle. Thus we write

$$
\eta=\frac{\mathrm{Wf}}{\mathrm{P}}
$$

where $\eta$ is the heart efficiency in pumping blood to the vascular system.

Equations (3), (8), (12), and (13) yield

$$
\mathrm{Q}=\frac{\eta \mathrm{cE} \Omega}{\mathrm{P}_{\mathrm{ss}}+\mathrm{P}_{\mathrm{ps}}}
$$

Equation (14) is useful to investigate the cardiopulmonary response to exercise. For numerical calculations, we shall rewrite the equation in a more convenient form. Since the systolic pulmonary pressure $\mathrm{P}_{\mathrm{ps}}$ is seven times smaller than the systolic systemic pressure $\mathrm{P}_{\mathrm{ss}}$ (Higginbotham et al., 1986; Milnor, 1990), we write Equation (14) as

$$
\mathrm{Q}=\frac{\mathrm{rE} \Omega}{1.14 \mathrm{P}_{\mathrm{ss}}}
$$

where

$$
\mathrm{r}=\eta \mathrm{c}
$$

We shall call $\mathrm{r}$ efficiency index of the heart.

The energy released in metabolic reactions, for a typical diet, is $\mathrm{E}=5.0 \mathrm{kcal} /\left(\right.$ liter of $\mathrm{O}_{2}$ ) (Milnor, 1990). Introducing this value into Equation (15) we obtain

$$
\mathrm{Q}=\frac{1.38 \times 10^{5} \mathrm{r} \Omega}{\left\{\mathrm{P}_{\mathrm{ss}}\right\}}
$$


where $\left\{\mathrm{P}_{\mathrm{ss}}\right\}$ is the numerical value of $\mathrm{P}_{\mathrm{ss}}$ in $\mathrm{mmHg}(1 \mathrm{mmHg}=0.133 \mathrm{kPa})$. For example, if $\mathrm{P}_{\mathrm{ss}}$ $=120 \mathrm{mmHg}$, then $\left\{\mathrm{P}_{\mathrm{ss}}\right\}=120$.

\subsection{Cardiopulmonary response to exercise}

Exercise provides a powerful tool that permits the study of the regulation of the cardiovascular system under controlled and reproducible conditions. Exercise more than any other stress taxes the regulatory ability of the cardiovascular system. More is learned about how a system operates when it is forced to perform than when it is idle.

We shall use Equation (17) and experimental data published in the literature for calculating the efficiency index of the heart $r$.

Higginbotham and collaborators (Higginbotham et al., 1986) have measured several quantities of the cardiovascular dynamics, during upright exercise in normal man. The study population consisted of 24 healthy males aged 20-50 years. Subjects varied from $63 \mathrm{~kg}$ to $103 \mathrm{~kg}$ in weight and from $173 \mathrm{~cm}$ to $185 \mathrm{~cm}$ in height; body surface area (a quantity that depends on the mass and height of the person, according to the empirical formula given below) ranged from $1.65 \mathrm{~m}^{2}$ to $2.10 \mathrm{~m}^{2}$. Those investigators have not published the values of cardiac output but the values of cardiac index, which is defined by

$$
\mathrm{I}=\frac{\mathrm{Q}}{\mathrm{A}}
$$

where I is the cardiac index, $\mathrm{Q}$ the cardiac output, and A the body surface area. Cardiologists use the cardiac index to compare the pumping capability of a patient to that of a healthy person, irrespective of the body size.

The body surface area, which depends on the mass and the height of the person, is calculated from the empirical formula (Cameron et al., 1999)

$$
\mathrm{A}=0.202 \mathrm{M}^{0.425} \mathrm{H}^{0.725}
$$

where $\mathrm{A}$ is the body surface area in $\mathrm{m}^{2}, \mathrm{M}$ the mass in kilogram, and $\mathrm{H}$ the height in meters.

\begin{tabular}{|c|c|c|c|}
\hline & $\begin{array}{c}\mathrm{P}_{\mathrm{ss}} \\
(\mathrm{mmHg})\end{array}$ & $\begin{array}{c}\Omega \\
\text { (liter } / \mathrm{min} \text { ) }\end{array}$ & $\begin{array}{c}\mathrm{I} \\
\left(\text { liter.min } \mathrm{min}^{-1} \cdot \mathrm{m}^{-2}\right)\end{array}$ \\
\hline Rest & 136 & 0.33 & 3.0 \\
\hline Peak Exercise & 220 & 2.55 & 9.7 \\
\hline
\end{tabular}
Table 1 shows experimental data from Higginbotham et al. (1986).

Table 1. Experimental data from Higginbotham et al. (1986). $\mathrm{P}_{\mathrm{ss}}$ is the systemic systolic pressure, $\Omega$ the rate of oxygen consumption, and I the cardiac index.

Higginbotham and collaborators have not calculated the mean body surface area but they have just reported that the body surface area varied from $1.65 \mathrm{~m}^{2}$ to $2.10 \mathrm{~m}^{2}$, so that we shall take $A=(1.65+2.10) \mathrm{m}^{2} / 2=1.88 \mathrm{~m}^{2}$ as the mean value for the considered population. With the data shown in Table 1 and Equations (17) - (18) we have calculated the cardiac output $Q$ and the efficiency index $r=\eta c$. The results are shown in Table 2 .

The results show that the efficiency index $r$ is not constant but varies with the rate of oxygen consumption $\Omega$. In order to determine the form of the function $\mathrm{r}(\Omega)$, let us consider the ratepressure product that is defined as the heart rate times the systemic systolic pressure $\left(\mathrm{fP}_{\mathrm{ss}}\right)$. 


\begin{tabular}{|c|c|c|c|}
\hline & $\begin{array}{c}\Omega \\
\text { (liter/min) }\end{array}$ & $\begin{array}{c}\mathrm{Q} \\
\text { (liter/min) }\end{array}$ & $10^{2} \mathrm{r}$ \\
\hline Rest & 0.33 & 5.6 & 1.7 \\
\hline Peak Exercise & 2.55 & 18.2 & 1.1 \\
\hline
\end{tabular}

Table 2. Rate of oxygen consumption $\Omega$, cardiac output $Q$ and efficiency index $r=\eta$.

This quantity is clinically useful in case of ischemic heart disease. It has been experimentally observed that the rate-pressure product correlates linearly with the rate of oxygen consumption (Kitamura et al., 1972).

Equations (3) and (15) yield

$$
\mathrm{fP}_{\mathrm{sS}}=\frac{\mathrm{rE} \Omega}{1.14 \mathrm{~S}}
$$

Experiments show that the stroke volume $S$ increases in the transition from rest to exercise and then remains practically constant (Uehara et al., 2008; Rowell, 1986). On the other hand $r$ is a function of $\Omega$, so that differentiating Equation (20) we obtain

$$
\frac{\mathrm{d}\left(\mathrm{fP}_{\mathrm{sS}}\right)}{\mathrm{d} \Omega}=\frac{\mathrm{rE}}{1.14 \mathrm{~S}}+\frac{\mathrm{E} \Omega}{1.14 \mathrm{~S}} \frac{\mathrm{dr}}{\mathrm{d} \Omega}
$$

where we have neglected the variation of the stroke volume. The rate-pressure product correlates linearly with $\Omega$ if its derivative is constant. Thus, we write

$$
\frac{\mathrm{rE}}{1.14 \mathrm{~S}}+\frac{\mathrm{E} \Omega}{1.14 \mathrm{~S}} \frac{\mathrm{dr}}{\mathrm{d} \Omega}=\mathrm{K}
$$

where $\mathrm{K}$ is a constant. Equation (22) can be written as

$$
\mathrm{r}+\Omega \frac{\mathrm{dr}}{\mathrm{d} \Omega}=1.14 \mathrm{~S} \frac{\mathrm{K}}{\mathrm{E}}=\mathrm{b}
$$

where $\mathrm{b}$ is practically constant insofar as $\mathrm{S}$ is practically constant. Integrating Equation (23) we obtain

$$
r=\frac{a}{\Omega}+b
$$

where $\mathrm{a}$ is an integration constant. The constants $\mathrm{a}$ and $\mathrm{b}$ can be determined from experimental data.

From Equations (21) and (23) we obtain

$$
\frac{\mathrm{d}\left(\mathrm{f} \mathrm{P}_{\mathrm{sS}}\right)}{\mathrm{d} \Omega}=\mathrm{b} \frac{\mathrm{E}}{1.14 \mathrm{~S}},
$$

which is practically constant during exercise, so that Equation (20) describes the nearly linear correlation between $\mathrm{fP}_{\text {ss }}$ and $\Omega$ that has been experimentally observed (Kitamura et al., 1972).

Equation (24) and the data shown in Table 2 yield 


$$
\mathrm{a}=0.0023 \frac{\text { liter }}{\min }
$$

and

$$
\mathrm{b}=0.010 \text {. }
$$

By Equation (23), $r$ is practically constant and equal to $b$ for values of $\Omega$ such that

$$
\Omega>>\frac{\mathrm{a}}{\mathrm{b}} .
$$

Thus, from Equations (26)-(27) it can be seen that for $\Omega>>0.23$ liter $/ \mathrm{min}$. the efficiency index of the heart is practically constant. Since the value of $\Omega$ for the subject in exercise is $\Omega>1.00$ liter/min., we conclude that the efficiency index is practically constant during exercise.

The relation between cardiac output and the rate of oxygen consumption is practically linear, as shown by many experiments (Beck et al., 2006). Thus, assuming the linear relation

$$
\mathrm{Q}=\mathrm{A}+\mathrm{B} \Omega
$$

we obtain, from the data in Table 1 and Table 2

$$
\mathrm{A}=3.7 \frac{\text { liter }}{\min }
$$

and

$$
\mathrm{B}=5.7 .
$$

The value of the slope $B=5.7$ corresponds to the value expected for healthy individuals (Skarvan, 2000). Lower values indicate an inadequate augmentation of cardiac output in relation to oxygen demand.

For comparison, we shall estimate the efficiency index of the heart considering experimental data published by other investigators. In order to calculate the efficiency index $\mathrm{r}$ from Equation (17), it is necessary to measure the cardiac output $Q$, the rate of oxygen consumption $\Omega$, and the systemic systolic pressure $\mathrm{P}_{\mathrm{ss}}$. Poliner and collaborators (Poliner et al., 1980) have studied the left ventricle performance at rest and during multilevel exercise in seven normal subjects (six man and one woman) with a mean age of 26 years and a mean body surface area of $1.83 \mathrm{~m}^{2}$. Exercises were performed in a bicycle ergometer. They have measured the cardiac output $\mathrm{Q}$ and the systemic systolic pressure $\mathrm{P}_{\mathrm{ss}}$, but they have not measured the rate of oxygen consumption $\Omega$, so that in order to calculate the efficiency index $r=\eta c$ from Equation (16), it is necessary to provide the lacking data from other sources. Table 3 shows data from Poliner and collaborators (Poliner et al., 1980).

Beck and collaborators (Beck et al., 2006) have experimentally studied the relation between cardiac output and oxygen consumption during upright cycle exercise in healthy humans. They have submitted 72 healthy subjects, aged 20 to 40 years, to a cycle-ergometer exercise test. They have measured the cardiac output and the rate of oxygen consumption, but they have not measured the systemic systolic pressure. The mean height of the subjects was 173 $\mathrm{cm}$ and the mean weight was $72.1 \mathrm{~kg}$. Introducing these values into Equation (19) we obtain the value $A=1.85 \mathrm{~m}^{2}$ for the mean body surface area. Since the mean body surface area for the population studied by Beck and collaborators differs in less than $1 \%$ from the 
corresponding value for the population studied by Poliner and collaborators, we shall use the data of both publications to complement each other. Thus, for the same value of the cardiac output we shall use the systemic systolic pressure $\mathrm{P}_{\mathrm{ss}}$ measured by Poliner and collaborators and the rate of oxygen consumption $\Omega$ measured by Beck and collaborators. For each value of the cardiac output given by Poliner and collaborators (Poliner et al., 1980) we have obtained the rate of oxygen consumption $\Omega$ from Figure 3 of the paper published by Beck and collaborators (Beck et al., 2006). Table 4 shows the experimental data we have obtained from Beck and collaborators.

\begin{tabular}{|c|c|c|c|c|}
\hline & Rest & Stage I & Stage II & Peak exercise \\
\hline $\begin{array}{c}\mathrm{Q} \\
\text { (liter/min.) }\end{array}$ & 4.8 & 10.4 & 15.1 & 18.0 \\
\hline $\begin{array}{c}\text { Heart rate f } \\
\text { (beats/min.) }\end{array}$ & $89 \pm 5$ & $124 \pm 4$ & $165 \pm 4$ & $182 \pm 2$ \\
\hline $\begin{array}{c}\mathrm{P}_{\mathrm{ss}} \\
(\mathrm{mmHg})\end{array}$ & $125 \pm 5$ & $161 \pm 7$ & $190 \pm 8$ & $204 \pm 8$ \\
\hline
\end{tabular}

Table 3. Cardiac output $Q$, heart rate $f$, and systemic systolic pressure $P_{s s}$ from Poliner et al. (1980).

\begin{tabular}{|c|c|c|c|c|}
\hline & Rest & Stage I & Stage II & Peak exercise \\
\hline $\begin{array}{c}\mathrm{Q} \\
\text { (liter/min.) }\end{array}$ & 4.8 & 10.4 & 15.1 & 18.0 \\
\hline $\begin{array}{c}\Omega \\
\text { (liter/min.) }\end{array}$ & 0.19 & 1.18 & 2.00 & 2.51 \\
\hline
\end{tabular}

Table 4. Cardiac output $Q$ and oxygen consumption $\Omega$ from Beck et al. (2006)

By using Equation (17) and the values of $Q$ and $P_{\text {ss }}$ given in Table 3, and $\Omega$ given in Table 4, we have calculated the efficiency index $r$. The results are shown in Table 4 . It can be seen that the efficiency index decreases with the level of exercise.

\begin{tabular}{|c|c|c|c|c|}
\hline & Rest & Stage I & Stage II & Peak exercise \\
\hline $\begin{array}{c}\Omega \\
\text { (liter/min.) }\end{array}$ & 0.19 & 1.18 & 2.00 & 2.51 \\
\hline Efficiency index $\mathrm{r}$ & 0.023 & 0.010 & 0.010 & 0.011 \\
\hline
\end{tabular}

Table 5. Efficiency index $r$ as a function of the rate of oxygen consumption $\Omega$

Assuming that the efficiency index $r$ is a function of the rate of oxygen consumption of the form expressed by Equation (24), we have determined by the least -squares method the values of $a$ and $b$ that correspond to the best fitting to the experimental data given in Table 5. We have found

and

$$
\mathrm{a}=0.0027 \frac{\text { liter }}{\min }
$$

$$
\mathrm{b}=0.009
$$


with a correlation factor equal to $\mathrm{R}=0.9898$.

Figure 3 shows $\mathrm{r}$ as a function of $\Omega$, given by Equation (24), with a and b given, respectively, by Equation (32) and Equation (33).

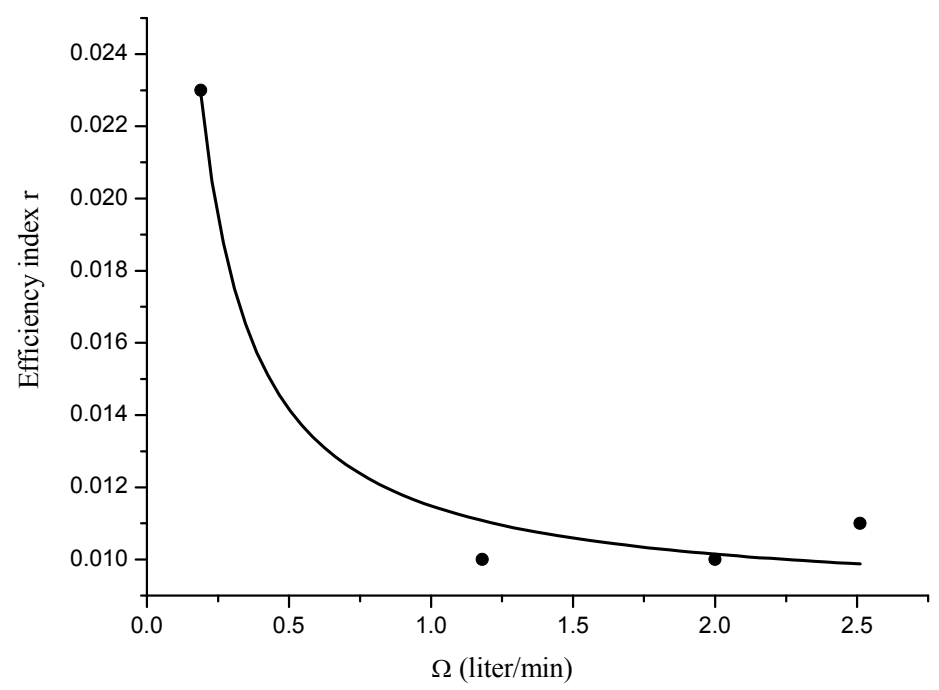

Fig. 3. Efficiency index $r$ as a function of the rate of oxygen consumption. The experimental points correspond to the values of $r$ given in Table 5 .

The results (32) - (33) show that the values of a and b, obtained from data published by Poliner and collaborators (Poliner et al., 1980) and Beck and collaborators (Beck et al., 2006), are not very different from that ones obtained from Higginbotham 's data (Higginbotham et al, 1986). Therefore, we conclude that, according to experimental data, the efficiency index of the heart $\mathrm{r}$ is larger for the subject at rest than in exercise, and is practically constant for higher levels of exercise.

Measuring the fraction, denoted by c, of oxygen consumed by the heart relatively to the total oxygen consumed by the body, the efficiency of the heart can be calculated as $\eta=r / c$. For a subject consuming oxygen at the rate $\Omega=0.25$ liter/minute, the heart consumes oxygen at the rate $\Omega_{\mathrm{H}}=0.035$ liter $/$ minute (Rowell, 1993), so that $\mathrm{c}=\Omega_{\mathrm{H}} / \Omega=0.14$. With these data and Equations (16), (24), (32)-(33) we obtain $\eta=0.14$, which agrees with the result $\eta=0.13$ reported in the literature (Blick \& Stein, 1977).

\subsection{Linearity of the relation between cardiac output and oxygen consumption}

The relationship between cardiac output and oxygen consumption during exercise has generally been assumed to be linear. Beck and collaborators have made experimental studies to test that assumption (Beck et al., 2006). They have used a statistical approach for analyzing the experimental data. We shall use Equation (15) to discuss the question of the linearity of the relation between cardiac output and oxygen consumption.

Assuming the linear relation expressed by Equation (29) and by using the least- squares method we have determined the values of A and B that best fit the experimental data shown in Table 3. We have found 


$$
\mathrm{A}=3.7 \frac{\text { liter }}{\min }
$$

and

$$
\mathrm{B}=5.7
$$

with a correlation factor equal to $\mathrm{R}=0.9999$. We note that the values of $\mathrm{A}$ and $\mathrm{B}$ are the same as those ones, given by Equations (30)-(31), obtained by using Higginbotham's data (Higgibotham et al., 1986). Figure 4 shows cardiac output $Q$ as a function of the rate of oxygen consumption $\Omega$.

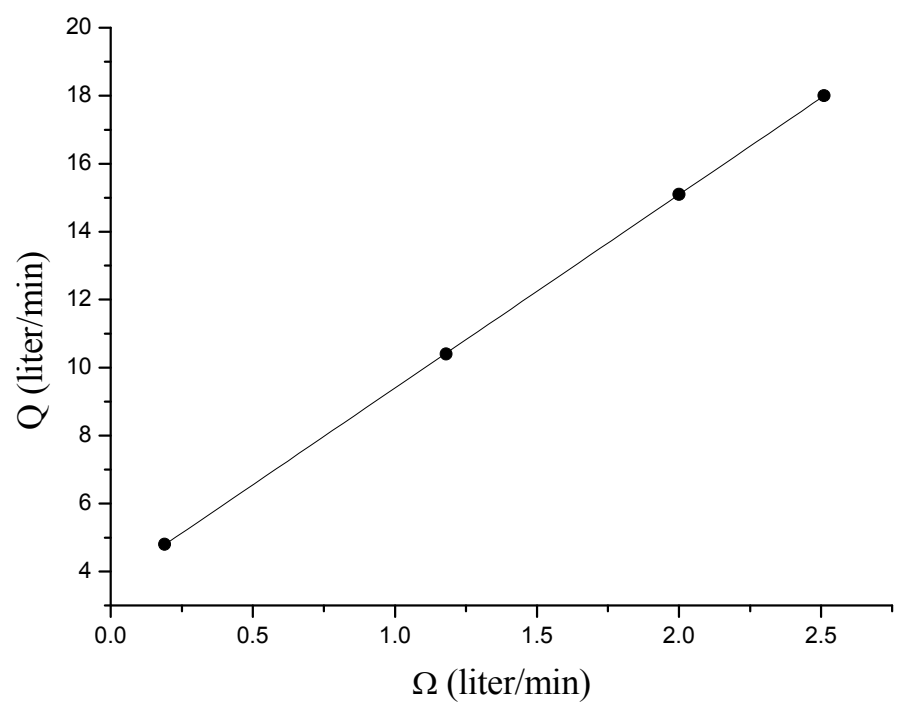

Fig. 4. Cardiac output $Q$ as a function of the rate of oxygen consumption $\Omega$.

Let us now consider the behavior of the systemic systolic pressure $P_{s s}$. Equations (3),(20), (24) and (29) yield

$$
\mathrm{P}_{\mathrm{ss}}=\frac{\mathrm{E}(\mathrm{a}+\mathrm{b} \Omega)}{1.14(\mathrm{~A}+\mathrm{B} \Omega)}
$$

from which we obtain

$$
\frac{\mathrm{dP}_{\mathrm{SS}}}{\mathrm{d} \Omega}=\frac{\mathrm{E}(\mathrm{bA}-\mathrm{aB})}{1.14(\mathrm{~A}+\mathrm{B} \Omega)^{2}}
$$

and

$$
\frac{\mathrm{d}^{2} \mathrm{P}_{\mathrm{ss}}}{\mathrm{d} \Omega^{2}}=-\frac{2 \mathrm{BE}(\mathrm{bA}-\mathrm{aB})}{1.14(\mathrm{~A}+\mathrm{B} \Omega)^{3}}
$$

Equations (37) and (38) show that if $(\mathrm{bA}-\mathrm{aB})>0$ then $\mathrm{d} \mathrm{P}_{\mathrm{ss}} / \mathrm{d} \Omega>0$, and $\mathrm{d}^{2} \mathrm{P}_{\mathrm{ss}} / \mathrm{d} \Omega^{2}<0$, so that in this case the systemic systolic pressure $P_{\mathrm{ss}}$ would be an increasing function of the 
rate of oxygen consumption $\Omega$ with a downwards concavity. On the other hand if $(\mathrm{bA}-\mathrm{aB})$ $<0$, then $\mathrm{P}_{\mathrm{ss}}$ would be a function that decreases with $\Omega$, which contradicts experimental data. Therefore, we must have $(\mathrm{bA}-\mathrm{aB})>0$ or, equivalently, $\mathrm{A} / \mathrm{B}>\mathrm{a} / \mathrm{b}$, which is satisfied by the values of $a, b, A$, and B, given, respectively, by the results (26),(27), (30), and (31).

For a typical diet, the caloric equivalent per liter of consumed oxygen is $\mathrm{E}=5.0 \mathrm{kcal} /$ (liter of $\mathrm{O}_{2}$ ) (Milnor, 1990; Cameron et al., 1999). Introducing this value into Equations (36)-(37) we obtain

$$
\left\{\mathrm{P}_{\mathrm{ss}}\right\}=1.38 \times 10^{5} \frac{(\mathrm{a}+\mathrm{b} \Omega)}{(\mathrm{A}+\mathrm{B} \Omega)}
$$

and

$$
\frac{\mathrm{d}\left\{\mathrm{P}_{\mathrm{sS}}\right\}}{\mathrm{d} \Omega}=1.38 \times 10^{5} \frac{(\mathrm{bA}-\mathrm{aB})}{(\mathrm{A}+\mathrm{B} \Omega)^{2}}
$$

where $\left\{\mathrm{P}_{\mathrm{ss}}\right\}$ is the numerical value of the systemic systolic pressure $\mathrm{P}_{\mathrm{ss}}$ in $\mathrm{mmHg}$. Equations (39)-(40) are convenient for numerical calculations. Figure 5 shows $P_{s s}$ as a function of the rate of oxygen consumption $\Omega$.

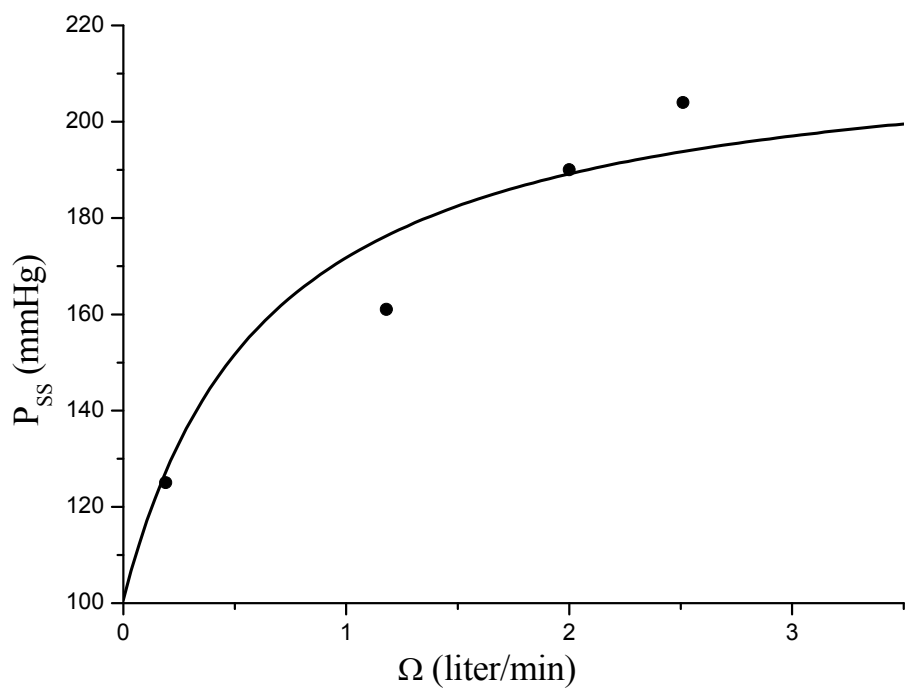

Fig. 5. Systemic systolic pressure $P_{s s}$ as a function of the rate of oxygen consumption $\Omega$. The experimental points correspond to the values given in Table 3.

For large values of $\Omega$ such that $B \Omega>$ A, we have also $b \Omega>>$, because $A / B>a / b$. In this case Equation (39) can be reduced to

$$
\left\{\mathrm{P}_{\mathrm{ss}}\right\}=1.38 \times 10^{5} \frac{\mathrm{b}}{\mathrm{B}}
$$

Introducing the values of $\mathrm{b}$ and $\mathrm{B}$ given, respectively, by (27) and (31) we get $\mathrm{P}_{\mathrm{ss}}=242$ $\mathrm{mmHg}$. 
Assuming the linear relation $\mathrm{Q}=\mathrm{A}+\mathrm{B} \Omega$ between cardiac output $\mathrm{Q}$ and the rate of oxygen consumption $\Omega$, and considering the behavior of the efficiency index of the heart $r$, expressed by Equation (24), we have shown that during exercise the systemic systolic pressure $P_{s s}$ is an increasing function of $\Omega$, which has a derivative that decreases with the level of exercise, so that the systemic systolic pressure approaches a limiting value with increasing the exercise level.

\subsection{Ischemic heart disease and essential hypertension}

Blood supply to the myocardium (cardiac muscle) via coronary arteries is normally abundant. Inadequate blood supply to the heart (myocardial ischemia or coronary ischemia) leads to the activation of anaerobic processes for generating energy (Chandler et al., 2002; Stanley et al., 1997). Easily measured predictors of myocardial blood flow are necessary to evaluate objectively functional improvement in patients with ischemic heart disease. The ratepressure product can be a useful parameter for this purpose, since by Equation (20) it is an index of myocardial oxygen consumption. It has been observed that in case of angina pectoris (chest pain caused by myocardial ischemia) the pain occurs during exercise, in a given patient, at a characteristic value of the rate-pressure product (Kitamura et al., 1972; Gobel et al., 1978).

In the presence of ischemic heart disease, Equation (8), which gives the power consumed by the heart, must be generalized to include anaerobic processes for generating energy. Thus, we write

$$
\mathrm{P}=\mathrm{Ec} \Omega+\chi,
$$

where $X$ is the rate of energy provided by anaerobic processes. Equation (15) for the cardiac output is modified as

$$
\mathrm{Q}=\frac{\eta(\mathrm{cE} \Omega+\chi)}{1.14 \mathrm{P}_{\mathrm{ss}}}
$$

and Equation (20) for the rate-pressure product is modified as

$$
\mathrm{fP}_{\mathrm{ss}}=\frac{\eta(\mathrm{cE} \Omega+\chi)}{1.14 \mathrm{~S}}
$$

Let us call $\mathrm{L}$ the value of the rate-pressure product at which occurs chest pain, during exercise, in a given patient with angina pectoris. Thus, we write

$$
\left(\mathrm{f}_{\mathrm{ss}}\right)_{\mathrm{L}}=\mathrm{L}
$$

so that for $\mathrm{fP}_{\mathrm{ss}}<\mathrm{L}$, the rate-pressure product is given by Equation (20) and for fPss $\geq \mathrm{L}$, it is given by Equation (44).

The rate-pressure product is related to the mechanical power Wf generated by the heart, as can be seen from Equation (12), which we write as

$$
\mathrm{Wf}=1.14 \mathrm{P}_{\mathrm{ss}} \mathrm{Sf}
$$

since $\mathrm{P}_{\mathrm{ps}}$ is about seven times smaller than $\mathrm{P}_{\mathrm{ss}}$. Then if $\mathrm{Wf} \geq 1.14 \mathrm{LS}$ chest pain occurs, indicating the activation of anaerobic processes for generating energy. 
Let us write the efficiency index of the heart as $r_{i}=\eta c_{i}$ for a patient with ischemic heart disease. Since the fraction $c$ of oxygen consumed by a normal heart is larger than the corresponding value $c_{i}$ for the diseased heart, we have $r_{i}<r$. Therefore the efficiency index of the heart can be a clinically useful parameter to distinguish a diseased heart from a normal one. It would be interesting to make experiments for verifying this possibility.

Let us now consider essential hypertension, a disease in which the systemic resistance, defined by Equation (5) is higher than the normal one, due to constriction of arterioles (small arteries that can constrict and dilate). In this case, an arterial pressure higher than the normal is required to maintain the cardiac output at a normal value. This means that the systemic systolic pressure $P_{\mathrm{ss}}$ is higher than the normal pressure. Then, Equation (15) shows that the rate of oxygen consumption $\Omega$ must be higher than the normal rate to maintain the cardiac output at a normal value, so that the line that represents cardiac output as a function of the rate of oxygen consumption would be shifted towards the right relatively to the normal line shown in Figure 4.

\section{Conclusion}

By applying a thermodynamic approach we have derived a relation between cardiac output and the rate of oxygen consumption. Using the derived relation and experimental data published in the literature we have estimated the efficiency index of the heart. We have also derived an equation for the rate-pressure product as a function of the rate of oxygen consumption. The derived equation explains the practically linear correlation observed between the rate-pressure product and the rate of oxygen consumption by the heart. This work suggests a possible clinical application of the efficiency index of the heart as a parameter to distinguish a diseased heart from a normal one. This possibility must be investigated experimentally in order to verify if it is clinically useful. The theory presented in this work provides a theoretical basis for designing experiments to investigate the cardiopulmonary response to exercise.

\section{References}

Acierno, L. J. (2000). Adolf Fick: Mathematician, Physicist, Physiologist. Clinical Cardiology, Vol. 23, Part 5 (2000), 390-393, ISSN 0160-9289

Beck, K. C.; Randolph, L. N.; Bailey, K. R.; Wood, C. M.; Snyder, E. M. \& Johnson,B. D. (2006). Relationship between cardiac output and oxygen consumption during upright cycle exercise in healthy humans. Journal of Applied Physiology, Vol. 101, No. 5, (May 2006), 1474-1480, ISSN 8750-7587

Blick, E. F.; \& Stein, P. D. (1977). Work of the heart: A general thermodynamic analysis. Journal of Biomechanics, Vol. 10, No. 9, (Sept 1977) 589-595, ISSN 0021-9290

Burkhoff, D. \& Sagawa, K. (1986). Ventricular efficiency predicted by an analytical model. American Journal of Physiology, Vol. 250, No. 6, (June 1986), p. R1021-R1027, ISSN: 0002-9513

Cameron, J. R..; Skofronick, J. G. \& Grant, R. M. (1999). Physics of the Body, 2nd edition,p.21, Medical Physics Publishing, ISBN 0-944838-91-X, Madison, Wisconsin, USA,

Chandler, M. P.; Huang, H.; McElfresh, T. A. \& Stanley, W. C. (2002). Increased monoxidative glycolysis despite continued fatty acid uptake during demaninduced myocardial ischemia. American Journal of Physiology - Heart and Circulatory Physiology, Vol. 282, No. 5, (May 2002), p. H1871-H1878, ISSN 1522-1539 
Gobel, F. L.; Nordstrom, L. A.; Nelson, R. R.; Jorgen, C. R. \& Wang, Y. (1978). The ratepressure product as an index of myocardial oxygen consumption during exercise in patients with angina pectoris. Circulation, Vol. 57, No. 3, (March 1978), 549-556, ISSN 0009-7322

Higginbotham, M. B.; Morris, R. S.; Williams, P. A.; McHale, P.A.; Coleman, R. E. \& Cobb, F. R. (1986). Regulation of stroke volume during submaximal and maximal upright exercise in normal man. Circulation Research, Vol. 58, No. 2, (February 1986), 281291, ISSN 0009-7330 (print); ISSN 1524-4571 (online)

Hoppensteadt, F. C. \& Peskin, C. S. (1992). Mathematics in Medicine and the Life Sciences, Springer-Verlag, ISBN 0-387-97639-6, New York, USA, p. 115

Kitamura, K.; Jorgensen, C. R.; Gobel, F. L.; Taylor, H. L. \& Wang, Y. (1972). Hemodynamic correlates of myocardial oxygen consumption during upright exercise. Journal of Applied Physiology, Vol. 32, No. 4, (April 1972), 516-522, ISSN 0021-8987

Milnor, W. R. (1990). Cardiovascular Physiology, Oxford University Press, p. 129, p. 130, p. 174, ISBN 0-19-505884-4, New York, USA,.

Poliner, L. R.; Deimer, G. J.; Lewis, S. E.; Parkey, R. W.; Blomqvist, C. G.; Willerson, J. T. (1980). Left ventricular performance in normal subjects: a comparison in the upright and supine positions. Circulation, Vol. 62, No. 3, (September 1980), 528-534, ISSN 0009-7322

Rowell, L. B. (1986). Human Circulation - Regulation During Physical Stress, Oxford University Press, p. 215, ISBN 0-19-504075-9, New York, USA.

Rowell, L. B. (1993). Human Cardiovascular Control, Oxford University Press, p. 205, ISBN 019-507362-2, New York, USA.

Skarvan, K. (2000). Ventricular performance. In: Cardiovascular Physiology, Priebe, H.-J. \& Skarvan, K., (Ed.), 27-72, BMJ Books, 2nd edition, ISBN 0-7279-1427-8, London, UK.

Sharma, N.; Okere, I. C.; Brunengraber, D. Z.; McElfresh, T. A.; King, K. L.; Sterk, J. P.; Huang, H.; Chandler, M. P. \& Stanley, W. C. (2005). Regulation of pyruvate dehydrogenase activity and citric acid cycle intermediates during high cardiac power generation. The Journal of Physiology, Vol. 562, Pt 2, (Jan 2005), 593-603, ISSN 0022-3751

Shapiro, E. (1972). Adolf Fick - Forgotten Genius of Cardiology. The American Journal of Cardiology, Vol.. 30, No. 6, (Nov 1972), 662-665, ISSN 0002-9149

Stanley, W. C.; Lopaschuk, G. D.; Hall, J. L. \& McCormack, J. G. (1997). Regulation of myocardial carbohydrate metabolism under normal and ischaemic conditions. Potential for pharmacological interventions. Cardiovascular Research, Vol. 33, No. 2, (Feb 1997), p. 243-257, ISSN 0008-6363

Uehara, M. \& Sakane, K. K. (2003). Physics of the cardiovascular system: An intrinsic control mechanism of the human heart. American Journal of Physics, Vol. 71, No. 4, (April 2003) 338-344, ISSN 0002-9505

Uehara, M. ; Sakane, K. K. \& Bertolotti, S. A. (2008). Thermodynamics of the heart: Relation between cardiac output and oxygen consumption. American Journal of Physics, Vol. 76, No. 6, (June 2008) 566-569, ISSN 0002-9505

Vary, T. C.; Reibel, D. R. \& Neely, J. R. (1981). Control of energy metabolism of heart muscle. Annual Review of Physiology, Vol. 43, 419-430, ISSN 0066-4278

Zhou, F; Yu, X.; Cabrera, M. C. \& Stanley, W. C. (2006). Role of Cellular Compartmentation in the Metabolic Response to Stress. Annals of the New York Academy of Sciences, Vol. 1080, 120-139, ISSN 0077-8923 (print); ISSN 1749-6632 (online) 


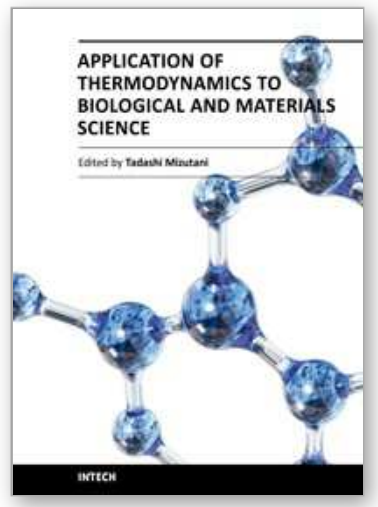

\author{
Application of Thermodynamics to Biological and Materials \\ Science \\ Edited by Prof. Mizutani Tadashi
}

ISBN 978-953-307-980-6

Hard cover, 628 pages

Publisher InTech

Published online 14, January, 2011

Published in print edition January, 2011

Progress of thermodynamics has been stimulated by the findings of a variety of fields of science and technology. The principles of thermodynamics are so general that the application is widespread to such fields as solid state physics, chemistry, biology, astronomical science, materials science, and chemical engineering. The contents of this book should be of help to many scientists and engineers.

\title{
How to reference
}

In order to correctly reference this scholarly work, feel free to copy and paste the following:

Uehara, Mituo and Sakane, Kumiko Koibuchi (2011). Thermodynamics of the Heart, Application of Thermodynamics to Biological and Materials Science, Prof. Mizutani Tadashi (Ed.), ISBN: 978-953-307-980-6, InTech, Available from: http://www.intechopen.com/books/application-of-thermodynamics-to-biological-andmaterials-science/thermodynamics-of-the-heart

\section{INTECH}

open science | open minds

\section{InTech Europe}

University Campus STeP Ri

Slavka Krautzeka 83/A

51000 Rijeka, Croatia

Phone: +385 (51) 770447

Fax: +385 (51) 686166

www.intechopen.com

\section{InTech China}

Unit 405, Office Block, Hotel Equatorial Shanghai

No.65, Yan An Road (West), Shanghai, 200040, China

中国上海市延安西路65号上海国际贵都大饭店办公楼 405 单元

Phone: +86-21-62489820

Fax: +86-21-62489821 
(C) 2011 The Author(s). Licensee IntechOpen. This chapter is distributed under the terms of the Creative Commons Attribution-NonCommercialShareAlike-3.0 License, which permits use, distribution and reproduction for non-commercial purposes, provided the original is properly cited and derivative works building on this content are distributed under the same license. 